\title{
Article \\ Aerodynamic Design, Analysis and Validation of a Small Blended-Wing-Body Unmanned Aerial Vehicle
}

\author{
Kelei Wang * and Zhou Zhou
}

College of Aeronautics, Northwestern Polytechnical University, Xi'an 710072, China; zhouzhou@nwpu.edu.cn

* Correspondence: craig-wang1@nwpu.edu.cn; Tel.: +86-18709247756

\begin{abstract}
This paper describes the aerodynamic design and assessment of a blended-wing-body (BWB) configuration under the distributed electric propulsion (DEP) installation constraints. The aerodynamic design rationale and process is described, as well as how the DEP system is considered and simplified in the optimization design process. Both the BWB configuration and the DEP induced effects are numerically simulated and analyzed using the Reynolds Averaged Navier-Stokes (RANS) computational fluid dynamics (CFD) flow solvers. To further demonstrate the feasibility and reliability of the design approach, the wind tunnel tests of a scaled model of the designed BWB configuration are carried out, and both the aerodynamic characteristics and the BWB surface flow are measured and analyzed. The results indicate the reliability and feasibility of the optimization design method introduced in this paper.
\end{abstract}

Keywords: blended-wing-body configuration; distributed electric propulsion; wind tunnel test; aerodynamic characteristics; optimization design

\section{Introduction}

With the rapid air-traffic demand and growth as well as the increasing environmen-

Citation: Wang, K.; Zhou, Z. Aerodynamic Design, Analysis and Validation of a Small BlendedWing-Body Unmanned Aerial Vehicle. Aerospace 2022, 9, 36. https://doi.org/10.3390/ aerospace 9010036

Academic Editor: Haixin Chen

Received: 6 December 2021

Accepted: 10 January 2022

Published: 11 January 2022

Publisher's Note: MDPI stays neutral with regard to jurisdictional claims in published maps and institutional affiliations.

Copyright: (C) 2022 by the authors. Licensee MDPI, Basel, Switzerland. This article is an open access article distributed under the terms and conditions of the Creative Commons Attribution (CC BY) license (https:// creativecommons.org/licenses/by/ $4.0 /)$. tal problems, many technology paths have been explored to improve civil aircraft flight efficiency and reduce the fuel consumption, among which the combination of distributed electric propulsion (DEP) and blended-wing-body (BWB) has attracted much attention. Compared with the traditional civil aircraft, the DEP-based BWB configuration has the ability to highly integrate the propulsors and the airframe for enhancement of the aeropropulsion integration benefits, and has shown great potential in vehicle efficiency improvements, propulsion efficiency improvements and noise pollution reductions [1-3]; it has therefore become a new research hotspot of aviation field in recent years, and a wide number of studies have been carried out to deal with issues related to aerodynamics, structures and propulsion systems of the DEP-based BWB conceptual aircrafts. For example, Rudi et al. [4] studied the performance benefits of DEP/BWB integration and reported a $5.3 \%$ fuel savings relative to the reference aircraft can be achieved, although the system is found to be particularly sensitive to duct losses. Andrew et al. [5] studied the integration benefits of DEP system and found that an $8 \%$ improvement in transonic efficiency can be achieved as compared to conventional under wing engine installations with equivalent propulsive areas. Michael et al. [6,7] carried out both computational and experimental study of the aero-propulsive coupling effects of a set of boundary-layer ingesting (BLI) fans mounted near the trailing-edge (TE) of a wing; the results revealed that significant interactions exist between the sectional aerodynamic performance and thrust level, and the changes of the stream-wise and stream-normal forces lift, drag, and pitching moment varies nonlinearly as a function of angle of attack and fan throttle setting. Sebastian and Tomas [8] make a series of propulsion system optimizations for an aircraft concept with fuselage boundary layer ingestion, resulting in a net reduction in mission fuel burn of $0.6 \% \sim 3.6 \%$ depending on technology assumption. All these efforts have shown that mutual interferences between the DEP system and the BWB airframe can be used to achieve 
significant improvements in both aerodynamic efficiency and propulsive efficiency, even though series of problems, such as the rather high fuel consumption of small turbofan engines and the low weight efficiency of distributed motors, still exist for the time being. Overall, the DEP-based BWB configuration can be considered as a viable option in the next-generation high-performance aerial vehicle designer's arsenal.

Despite the advantages, the adoption of the DEP system adds more geometric components and shape constraints to the BWB configuration, and may result in an airframe body strikingly different from typical BWB aircrafts, such as the wide-body airframe need for the DEP system installation and the sinking inlet design of the embedded propulsive pattern, etc., which significantly increase the difficulty and complexity of the BWB configuration design problem. Even though there are numbers of researchers [9-16] investigating the blended-wing-body configuration from different points of view, most of them focused on the layout form, planform or the optimization design method itself. Hence, it is necessary to carry out more extensive investigations on the aerodynamic design of BWB configuration under DEP considerations, thereby gaining a deeper awareness of the DEP-caused design difficulties. This is the topic of the present work.

To best address these issues discussed above, a small DEP-based BWB unmanned aerial vehicle (UAV), as shown in Figure 1, is designed and studied by means of computational fluid dynamics (CFD) [17] and wind tunnel test. It can be seen that the present DEP-based BWB UAV use unique tailless configuration with high-level integration between the wing, the fuselage, and an array of small engines distributed along the rear airframe under cowls, which is obviously different from the conventional BWB forms. Table 1 lists the overall dimensions, the flight conditions, and the cruise targets. It should be noted that the focus of the present DEP-based BWB configuration design is that the requirements of cruise lift, cruise pitching moment, static stability margin, and the maximum lift-drag ratio need to be met at the same time at cruise. This is also the primary goal of the design optimization in this paper.

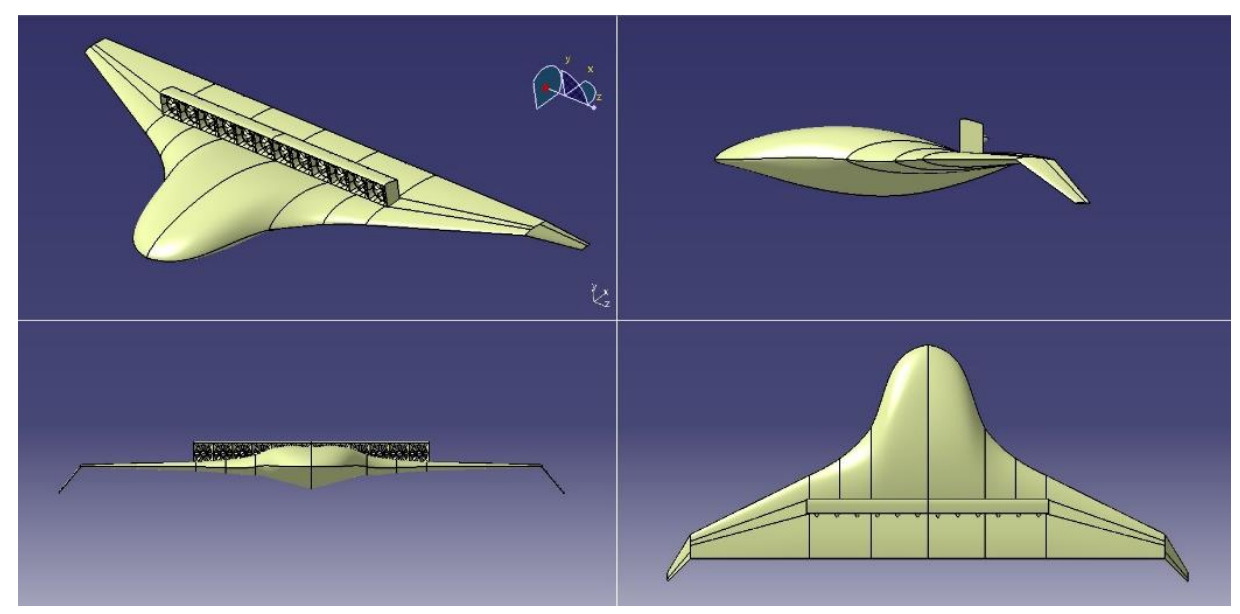

Figure 1. Sketch of the DEP-based BWB UAV conceptual configuration. 
Table 1. Reference dimensions, flight conditions, and cruise targets of the present DEP-based BWB UAV.

\begin{tabular}{cc}
\hline Parameter & Value \\
\hline Reference area & $S_{\text {ref }}=3.40 \mathrm{~m}^{2}$ \\
Reference chord & $C_{\text {ref }}=0.78 \mathrm{~m}$ \\
Reference span & $b=4.40 \mathrm{~m}$ \\
Moment reference point (MRP) location & $(1.10,0,0) \mathrm{m}$ \\
Total mass & $m=80 \mathrm{~kg}$ \\
Altitude & $H=5000 \mathrm{~m}$ \\
Velocity & $V=200 \mathrm{~km} / \mathrm{h}$ \\
Chord Reynolds number & $R e_{\mathrm{C}}=2.0 \times 10^{6}$ \\
Cruise lift coefficient & $C_{\mathrm{L}, \text { cruise }}=0.2$ \\
Cruise pitching moment coefficient & $C_{\mathrm{M}, \text { cruise }} \approx 0.0$ \\
Static stability margin & $\Delta C_{\mathrm{M}} / \Delta C_{\mathrm{L}} \leq-5 \%$ \\
Maximum lift-to-drag ratio & $\left(C_{\mathrm{L}} / C_{\mathrm{D}}\right)_{\text {max }} \geq 16.0$ \\
Cruise thrust & $T_{\text {cruise }}=50 \mathrm{~N}$ \\
\hline
\end{tabular}

The remainder of this paper is organized as follows. In Section 2, the design methods developed for the present DEP-based BWB UAV are described in detail, including the DEP considerations and simplifications, the airfoil parameterization, the numerical simulation and the optimization design process. In Section 3 , the aerodynamic performances of the BWB configurations are compared and analyzed. The experimental validations are shown in Section 4. Summary and conclusions follow in Section 5.

\section{Design Methods under DEP Considerations}

\subsection{DEP Considerations and Simplification}

The preliminary studies of our task group have shown that the cruise aerodynamic performance of the present UAV mainly depend on the BWB characteristics; moreover, the DEP system at the specified low thrust level leaves only slight effects on the liftto-drag performance of the BWB configuration, but has a relatively large effects on the pitching moment performance. Thus, it is decided that the scope of the aerodynamic design study is to only design the BWB configuration under DEP considerations (mainly under the geometric constraints caused by the DEP installation), and several characteristic sections are selected to be optimized while the BWB planform should remain fixed as much as possible.

As shown in Figure 2, the design object of this study can be simplified into the BWB model with a planar space existing on the upper surface for the DEP installation, and there are in total 4 characteristic sections with no twist angle along the span being chosen to model the whole BWB configuration. Moreover, due to that the planar space plays a significant role in determining the aerodynamic performance of the BWB configuration, the length of the planar space is kept unchanged in both chord-wise and span-wise directions, and the DEP thrust line compared with the center of gravity (CG) is also maintained as well throughout the design process. Table 2 illustrates the span-wise location and related parameters of each characteristic sectional airfoil, and all these parameters will be treated as the geometric constraints in the following design process.

Table 2. Characteristic sectional airfoil parameters.

\begin{tabular}{ccccc}
\hline Parameter & Section A & Section B & Section C & Section D \\
\hline Span-wise location & $\mathrm{zA}=0 \mathrm{~m}$ & $\mathrm{zB}=0.48 \mathrm{~m}$ & $\mathrm{zC}=1.00 \mathrm{~m}$ & $\mathrm{zD}=2.00 \mathrm{~m}$ \\
Thickness & $\mathrm{tA}=0.33 \mathrm{~m}$ & $\mathrm{tB}=0.16 \mathrm{~m}$ & $\mathrm{tC}=0.10 \mathrm{~m}$ & $\mathrm{tD}=0.03 \mathrm{~m}$ \\
Chord length & $\mathrm{cA}=1.80 \mathrm{~m}$ & $\mathrm{cB}=1.10 \mathrm{~m}$ & $\mathrm{cC}=0.70 \mathrm{~m}$ & $\mathrm{cD}=0.25 \mathrm{~m}$ \\
Parameter & Section A & Section B & Section C & Section D \\
\hline
\end{tabular}




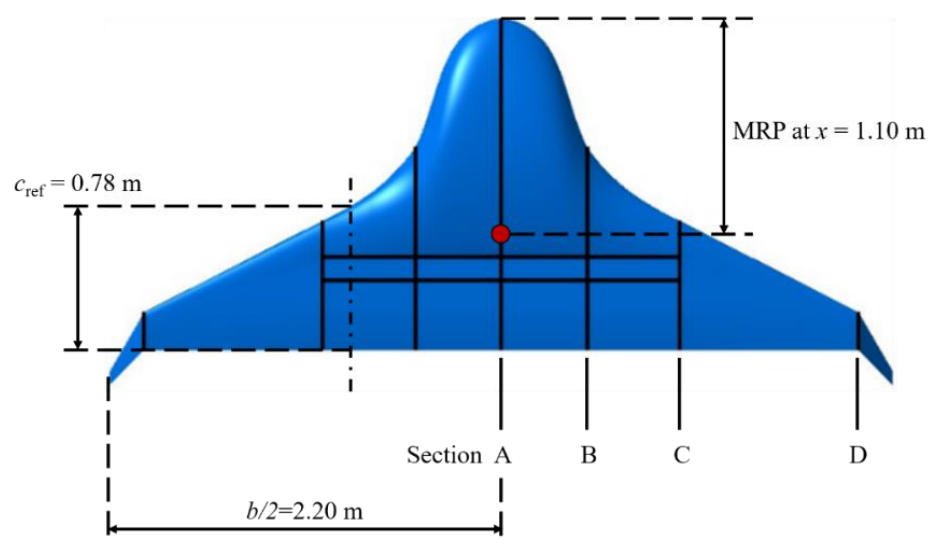

(a)

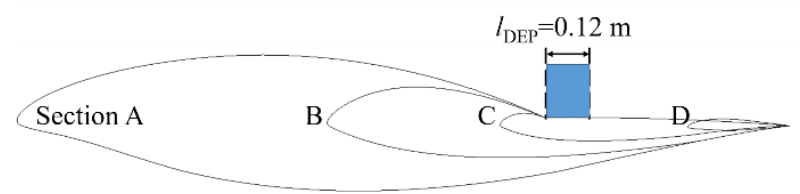

(b)

Figure 2. Baseline BWB configuration under DEP installation constraints. (a) BWB planform sketch. (b) Sectional airfoil profiles.

Moreover, simplifications of the complicated DEP geometry that consists of 14 ducted fans (see Figure 3) are carried out by our task group to rapidly evaluate the DEP induced effects on the BWB configuration. The external ducts are simplified into the rectangular wall surface without thickness, and the rotor and stator blades are ignored and represented by the setting of fan boundary condition within the ducted flow passage. After considering the rotor and stator thrust contribution at its cruise state comprehensively, the fan boundary is set at $30 \%$ chord-length location of the DEP box.

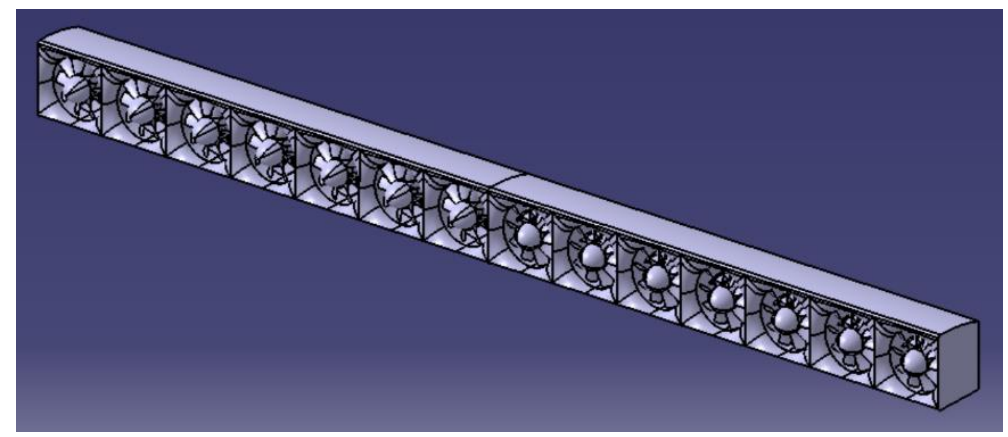

Figure 3. CAD model of the DEP system.

\subsection{Sectional Airfoil Parameterization}

In this study, the sectional airfoil profiles are quite different from that of the conventional airfoils because of the existence of the specified planar segment. It is necessary to develop a geometry parametric method that can meet current needs. As shown in Figure 4, the sectional airfoil is decomposed into three parts and parameterized in a separated way. 


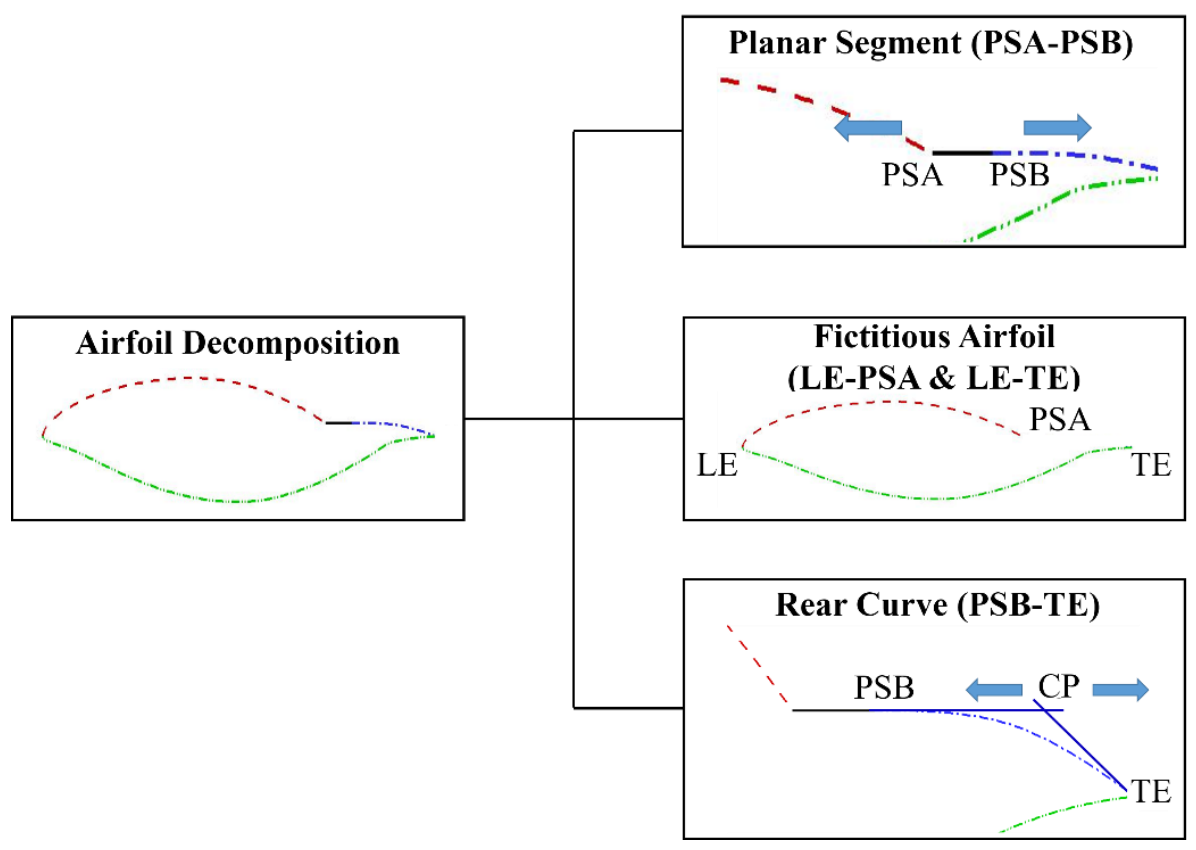

Figure 4. Sketch of the developed sectional airfoil parametric method.

\subsubsection{Planar Segment Parameterization (PSA-PSB)}

As described above, the sectional airfoil is optimized to obtain the design performance targets under the premise that both length and height of the specified planar segment on the upper surface remain constants. Consequently, it is able to define the PSA-PSB planar segment only with the chord-wise location of point PSA $\left(x_{\mathrm{PSA}}\right)$. Moreover, the variation range of the $x_{\mathrm{PSA}}$ has been determined as $1.20 \mathrm{~m} \leq x_{\mathrm{PSA}} \leq 1.60 \mathrm{~m}$, which aims to limit the designed configuration to a class of geometrically acceptable shapes.

\subsubsection{Fictitious Airfoil Parameterization (LE-PSA and LE-TE)}

Due to the consideration that the height of the specified planar segment on the upper surface remains constant, the LE-PSA profile can be simply enlarged to the local chord length along the $x$ axis by multiplying the $x$ coordinates by a factor $c / x_{\mathrm{PSA}}$, as shown in Figure 5, and then the fictitious airfoil profile can be generated and controlled using conventional parametric methods.

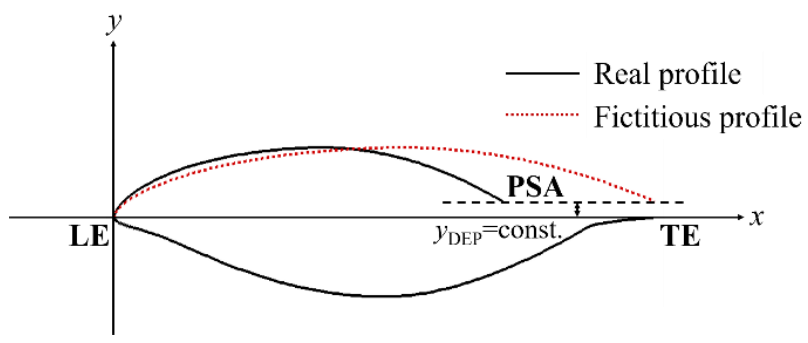

Figure 5. Generation of the sectional fictitious airfoil.

In this study, the Hicks-Henne bump functions [18] are used to control the fictitious airfoil profile, which enables separate modeling of the upper and lower surfaces of the baseline airfoil. The functions can be represented by the following equations: 


$$
\left\{\begin{array}{l}
y_{\text {upper }}=y_{\text {u-base }}+\sum_{k=1}^{4} c_{k} \cdot f_{k}(x) \\
y_{\text {lower }}=y_{1-\text { base }}+\sum_{k=1}^{4} c_{k+4} \cdot f_{k}(x) \\
f_{k}(x)=\sin ^{3}\left[\pi x^{e(k)}\right] \\
e(k)=\frac{\ln 0.5}{\ln x_{k}} ; x_{k}=[0.10,0.35,0.65,0.90]
\end{array}\right.
$$

where $y_{\mathrm{u} \text {-base }}$ and $y_{1 \text {-base }}$ are vertical coordinates of the upper and lower surfaces of the baseline airfoil, $x_{k}$ are horizontal coordinates of the prescribed control points with respect to the airfoil chord, $f_{k}(x)$ are the shape functions that will be added linearly to the baseline profile to achieve the desired design improvement and $c_{k}$ are the participation coefficients (design variables) that are associated with all the shape functions.

\subsubsection{Rear Curve Parameterization (PSB-TE)}

As shown in Figure 4, the quadratic spline with a control point $C$ is used for the rear curve parameterization. To further simplify the design problem, a geometric constraint that $y_{\mathrm{CP}}=y_{\mathrm{PSA}}=y_{\mathrm{PSB}}$ has been determined so that only the chord-wise location of the control point $\mathrm{CP}\left(x_{\mathrm{CP}}\right)$ is taken as the design variable, and its variation range can be always defined as $x_{\mathrm{PSB}}<x_{\mathrm{CP}}<x_{\mathrm{TE}}$.

As a result, the design variables and their boundaries of the sectional airfoil under the DEP installation constraints can be summarized in Table 3 . Obviously, $x_{\mathrm{PSA}}$ and $x_{\mathrm{CP}}$ are two common variables used by all the sectional airfoils with the planar segment PSAPSB under the DEP installation constraints. Moreover, the fictitious airfoil simplification method enables section A, B and C to be parameterized with the same set of parameters, which further simplify the multi-section design problem into a two-section design problem, thereby reducing the number of design variables and the complexity of the design problem.

Table 3. Design variables of the sectional airfoil under the DEP installation constraints.

\begin{tabular}{ccccc}
\hline Variable & Definition and Unit & Initial Value & Upper Bound & Lower Bound \\
\hline$x_{\mathrm{PSA}}$ & $\begin{array}{c}\text { chord-wise location of } \\
\text { point PAS (m) } \\
\text { participation }\end{array}$ & 1.30 & 1.60 & 1.20 \\
$c_{k=1 \sim 8}$ & $\begin{array}{c}\text { coefficients (1) } \\
\text { chord-wise location of } \\
\text { point CP }(\mathrm{m})\end{array}$ & 1.42 & -0.01 & 0.01 \\
$x_{\mathrm{CP}}$ & \begin{tabular}{c} 
poin \\
\hline
\end{tabular}
\end{tabular}

\subsection{Mesh Generation and CFD Solver}

The commercially available CFD package Fluent version 19.0 is used to simulate the quasi-steady flow-field around the BWB configuration in this study, and the computational mesh is generated by preprocessing codes Gridgen for two-dimensional airfoil and ICEM for three-dimensional model, respectively. The full three-dimensional Reynolds Averaged Navier-Stokes (RANS) governing equations are discretized by the standard cell centered finite volume scheme. Air is considered the ideal gas, and the turbulence effects are considered by using the k- $\omega$ shear stress transport (SST) turbulence model [19]. Moreover, the second-order accurate Roe flux-difference upwind scheme is used for the convective fluxes of turbulence equations, and the lower-upper symmetric Gauss-Seidel (LU-SGS) implicit method is adopted for the time integration.

Figure 6 displays the computational mesh around the baseline airfoil at section A. The O-topology grids with 361 cells in the stream-wise direction and 150 cells in the normal-to-wall direction is used. The boundary layer thickness was applied based on the Reynolds number of the flow, and the height of the first layer is set to be $0.001 \mathrm{~m}$ so that the non-dimensional y-plus falls in the range less than 2.0. 


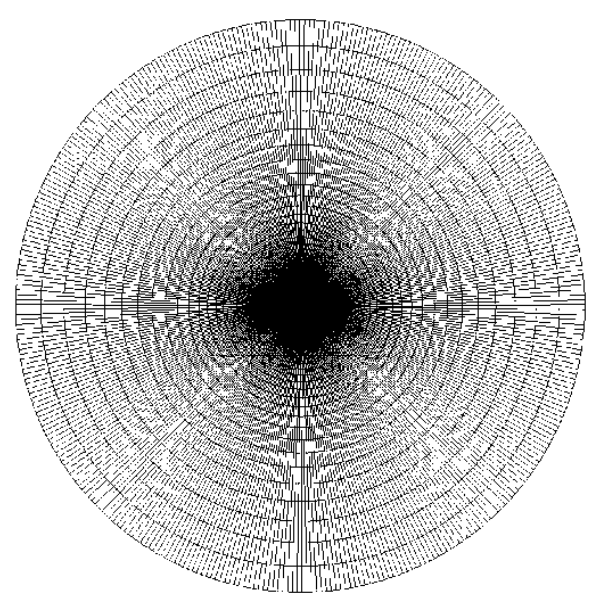

(a)

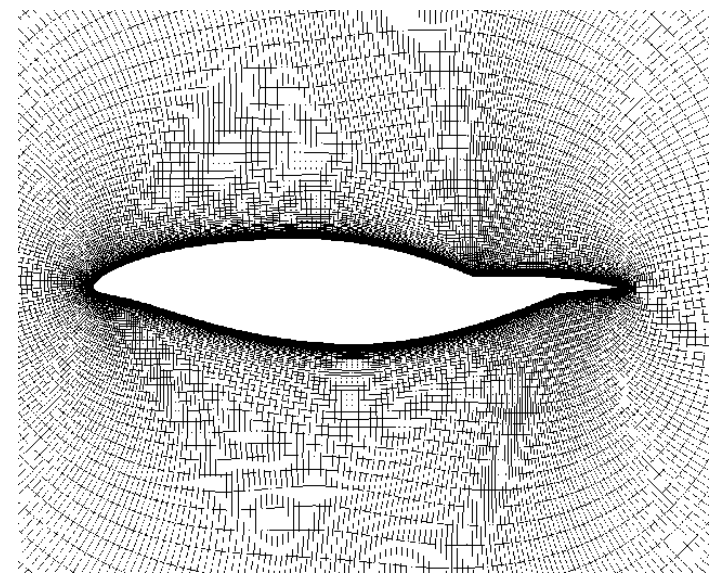

(b)

Figure 6. Computational mesh around the baseline airfoil at section A. (a) Computational domain. (b) Near-wall grids distribution.

Figure 7 shows the computational mesh used for the half model of the BWB configuration. The structured mesh is selected in the 3D model in order to achieve a proper accuracy versus reasonability of time for calculations, and the non-dimensional y-plus values at the first nodes are kept less than 2.0 as well to be consistent with that of the sectional airfoils. To examine the grid dependency in terms of results, a grid convergence study is conducted by using three levels of computational mesh with the same height of the first layer. Table 4 summarizes the total number of cells, computational time, and results corresponding to the three-grid level. The difference in the lift, drag and pitching moment coefficients are found to be less than $2 \%$ for the results from the fine and medium grids, and less than $5 \%$ for the results from the fine and coarse grids, and the required computational time to obtain converged solutions starting from free-stream conditions for the medium and coarse grids are about 6 and $4 \mathrm{~h}$ using the same workstation with dual core, eight threads and $256 \mathrm{G}$ memory. As a result, the medium grid is selected. In addition to the high quality of the aforementioned computational mesh, changes are applied automatically in the new grid by changing the sectional airfoils in the optimization process. Figure 8 shows the computational mesh used for the half model of the BWB configuration with simplified DEP system, its difference from the BWB computational mesh is mainly reflected in the addition of the rectangular wall surface and the fan boundary within the ducted flow passage as mentioned above.

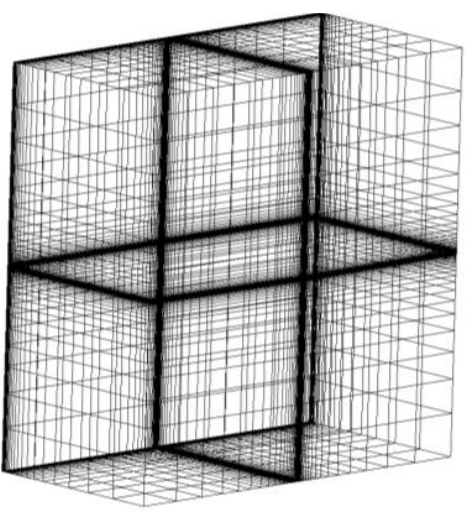

(a)

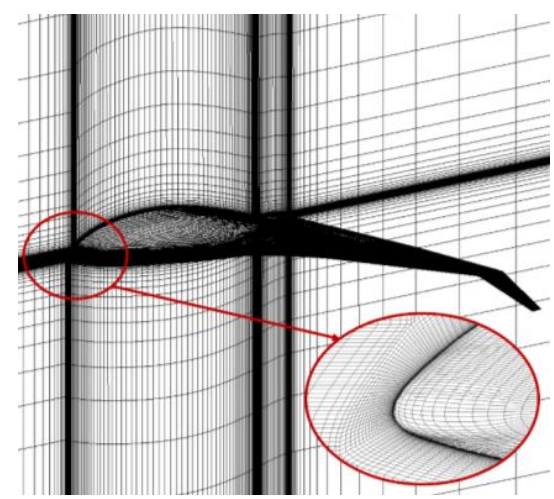

(b)

Figure 7. Computational mesh around the half model of the present BWB configuration. (a) Computational domain. (b) BWB surface mesh and center plane cells near LE. 
Table 4. Results of grid independence test for the present BWB configuration.

\begin{tabular}{cccccc}
\hline Grid & $\begin{array}{c}\text { Number of } \\
\text { Cells }\end{array}$ & $\begin{array}{c}\text { Computational } \\
\text { Time }\end{array}$ & $\begin{array}{c}C_{\mathbf{L}} \\
\text { Difference }\end{array}$ & $\begin{array}{c}C_{\mathbf{D}} \\
\text { Difference }\end{array}$ & $\begin{array}{c}C_{\mathbf{M}} \\
\text { Difference }\end{array}$ \\
\hline Fine & $6.7 \times 10^{6}$ & $11 \mathrm{~h}$ & $/$ & $/$ & $/$ \\
Medium & $3.3 \times 10^{6}$ & $6 \mathrm{~h}$ & $0.68 \%$ & $1.30 \%$ & $1.12 \%$ \\
Coarse & $1.0 \times 10^{6}$ & $4 \mathrm{~h}$ & $1.96 \%$ & $4.72 \%$ & $3.45 \%$ \\
\hline
\end{tabular}

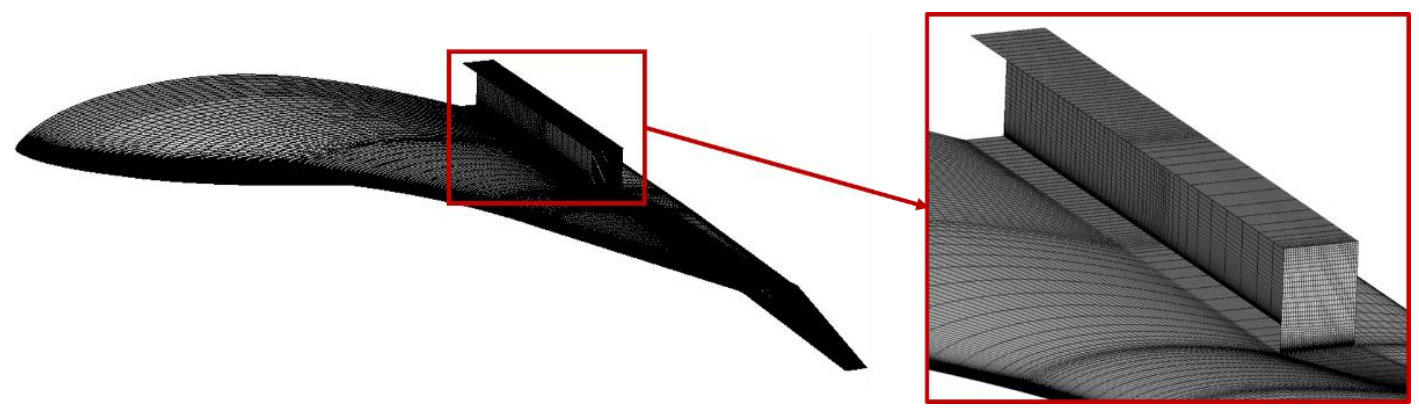

Figure 8. Computational mesh around the half model of the BWB configuration with simplified DEP system.

\subsection{Optimization Design Process}

Figure 9 illustrates the optimization design framework developed for the present BWB configuration under DEP installation constraints. It mainly consists of four parts: sectional airfoil design objective adjustments, sectional airfoil optimization design, BWB configuration design evaluation and DEP induced effects evaluation. The whole design process can be briefly summarized as: (1) allocate the design objectives of each sectional airfoil based on the numerical analysis of the BWB configuration design evaluation and DEP induced effects evaluation; (2) carry out the sectional airfoil optimization design in parallel. Since sections A, B and C are parameterized into the same fictitious airfoil based on the above simplification method, the optimization design of these three sectional airfoils will be carried out in one process, at the same time, the optimization design of section $\mathrm{D}$ will be conducted in another process; (3) update the BWB configuration geometry and the computational mesh, conduct the numerical simulation at $\alpha=2^{\circ}, 4^{\circ}$, and perform the objective function analysis, If the cruise targets as listed in Table 1 are satisfied, then go to the next step, if not, then go back to the first step; (4) establish the DEP-based BWB model, conduct the numerical simulation at $\alpha=2^{\circ}, 4^{\circ}$, and perform the objective function analysis, If the cruise targets as listed in Table 1 are satisfied, then output the design results and terminate the design process, if not, then go back to the first step. 


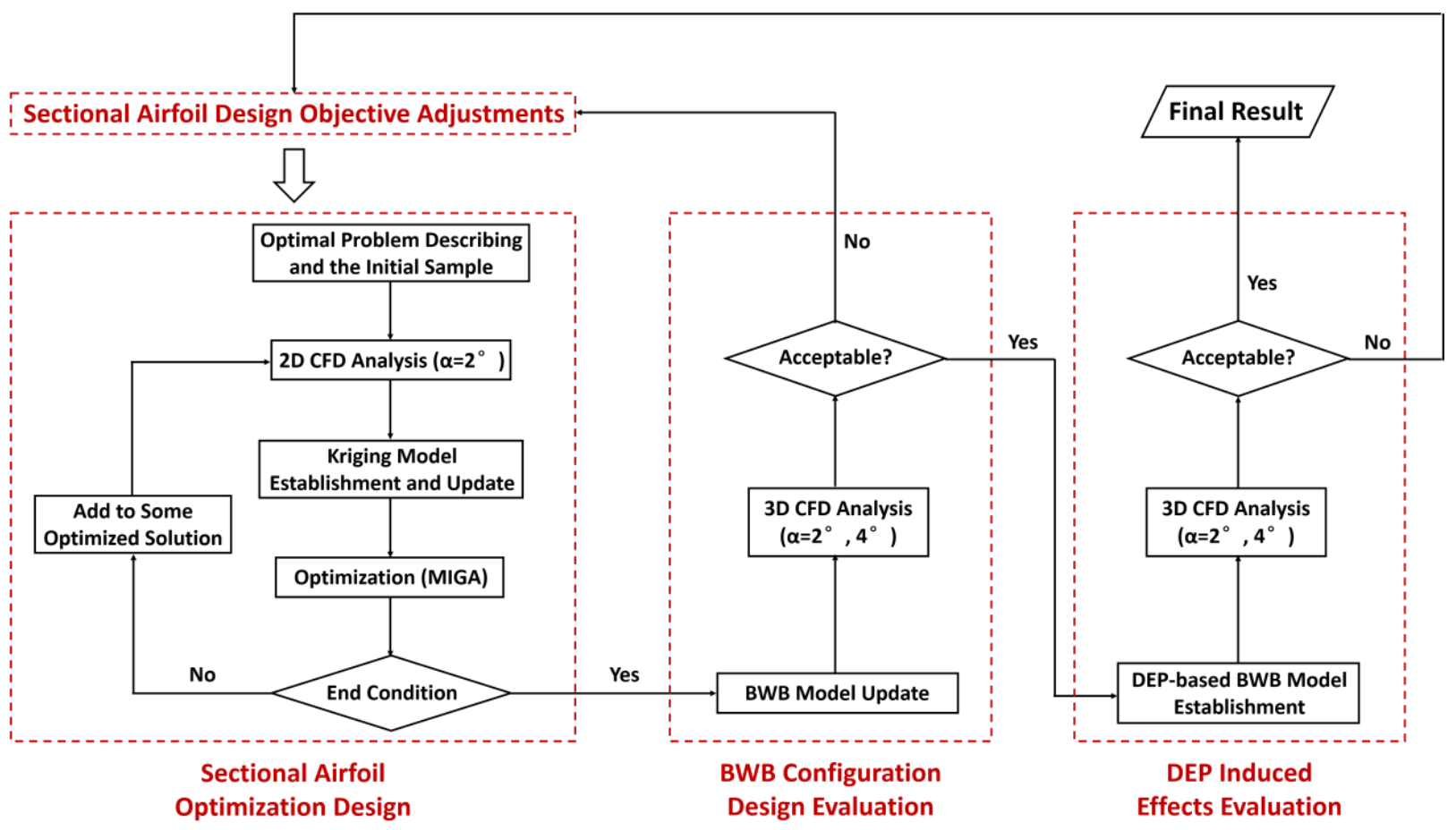

Figure 9. BWB configuration optimization design framework under DEP installation constraints.

As a result, there are totally 18 design variables for the optimization of sections A, $\mathrm{B}$ and $\mathrm{C}$ which are constrained by the planar segment for DEP system installation, and 16 design variables for section $\mathrm{D}$. The parallel sectional airfoil optimization design problem can be formulated as:

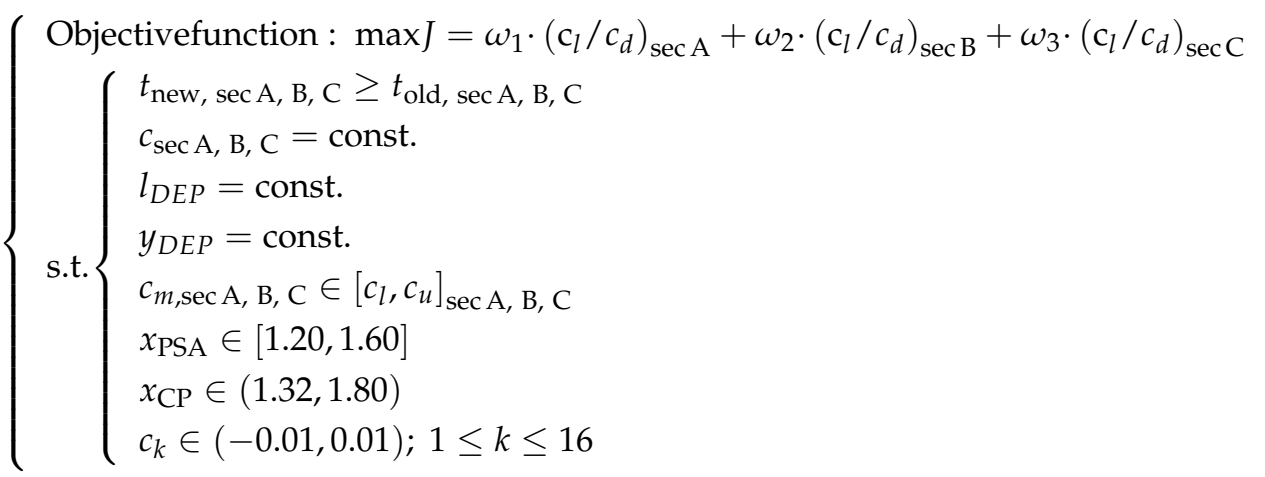

$$
\left\{\begin{array}{l}
\text { Objectivefunction : } \max J=\left(c_{l} / c_{d}\right)_{\sec \mathrm{D}} \\
\text { s.t. }\left\{\begin{array}{l}
t_{\text {new, } \sec \mathrm{D} \geq t_{\mathrm{old}} \sec \mathrm{D}} \\
c_{\mathrm{sec} \mathrm{D}=\mathrm{const.}} \\
c_{m, \sec \mathrm{D}} \in\left[c_{l}, c_{u}\right]_{\mathrm{sec} \mathrm{D}} \\
c_{k} \in(-0.01,0.01) ; 1 \leq k \leq 16
\end{array}\right.
\end{array}\right.
$$

where the lift-to-drag ratio of the sectional airfoil is chosen as the single objective, the weight coefficients for section A, B and C are $\omega_{1}=0.3, \omega_{2}=0.3$ and $\omega_{3}=0.4$, respectively. The thickness, the chord length, and both length and vertical location of the DEP system are constrained. The pitching moment $c_{m}$ generated by each sectional airfoil is set as the adjustment parameter while $c_{l}$ and $c_{u}$, respectively, represent the lower and upper limits of the adjustable interval. It should be noted that sections $\mathrm{A}, \mathrm{B}$ and $\mathrm{C}$ always have significant reflexed characteristics due to the existence of the planar segment, which makes their pitching moments congenitally towards nose-up. However, since the DEP system occupies 
nearly $1 / 2$ of the BWB configuration in the span-wise direction, this wide range of reflexed characteristics is not conducive to the improvement of overall lift-to-drag performance. Thus, we decided to constrain the pitching moment coefficients of the four sections to near 0.0 in the first round of optimization, so as to maximize the lift-to-drag performance at cruise, this is quite different from the design concept of conventional BWB configuration. In the following rounds of optimization, section A and B are used to adjust the pitching performance of the BWB configuration, while section $C$ and $D$ are used to adjust the lift-to-drag performance of the BWB configuration.

Moreover, the Kriging surrogate model [20] is used in the sectional airfoil optimization design process to improve the computational efficiency of the searching stage. For each section, a total of 80 sample points are estimated in parallel for constructing the Kriging surrogate model. Furthermore, some adaptive sampling procedures and the updating mechanism [21] by adding well-performance solution into the initial sample collection are used to further improve the accuracy of the Kriging surrogate model. Moreover, the multiisland genetic algorithm (MIGA) [22,23] is used to solve the sectional airfoil optimization problems. The control parameters of the MIGA are set as: (1) the size of the population is 100 (i.e., 10 islands and 10 individuals per island); (2) the probabilities of the crossover, mutation and migration operator are $0.9,0.2$ and 0.5 , respectively; (3) and the maximum evolution generation is 20 .

On the other hand, for both BWB configuration design evaluation and DEP induced effects evaluation, meeting the cruising targets at the same time, including the cruise lift, cruise pitching moment, static stability margin and the maximum lift-drag ratio, is the criterion for whether the optimization process continues or not.

\section{Results and Discussion}

\subsection{Sectional Foil Performance}

Figure 10 shows comparison of the sectional airfoil profiles. It can be found that the forward cambers of the optimized sectional airfoils are remarkably increased when compared to the baseline sectional airfoils. The locations of the maximum thickness of all these sectional airfoils are shifted backward, and the planar region significantly moves backward as well.

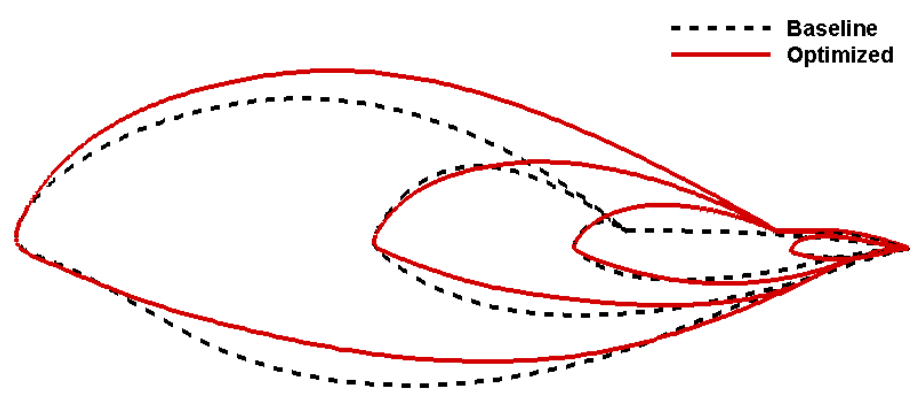

Figure 10. Baseline and optimized sectional airfoil profiles.

Figure 11 shows comparison of the sectional airfoil performance between before and after the optimization. The pitching moment coefficient is computed with the $1 / 4$ chordlength location taken as the moment action point for each sectional airfoil. It indicates that the lift-to-drag performance of the sectional airfoils, especially the section A and B, are significantly improved as the planar segment moves backward. Moreover, the pitching performance of the sectional airfoils are designed to be more near zero at all these angles of attack, which is quite different from the design concepts of conventional BWB configuration. This is because that the existence of the planar segment makes the airfoils at section A to C have to be negatively curved within their rear regions, which compensates the requirement for a BWB configuration to be reasonably well trimmed $\left(C_{M} \approx 0.0\right)$, and also allows the 
symmetrical airfoil at section A with the maximum chord length to be designed for better lift-to-drag performance rather than for better pitching performance.

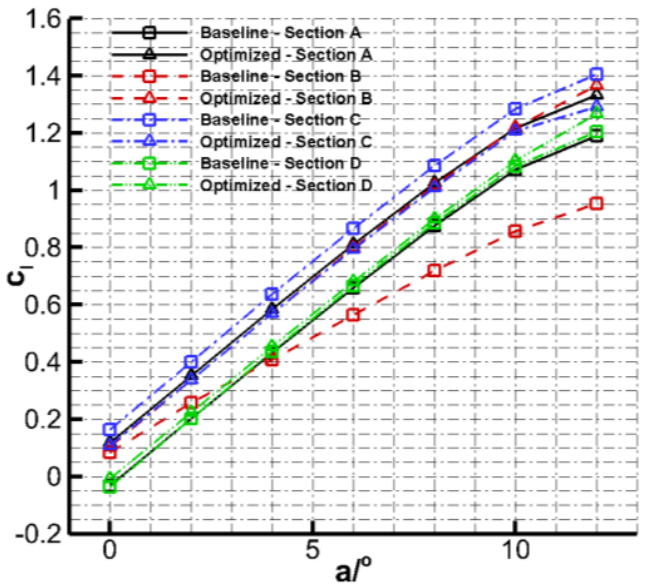

(a)

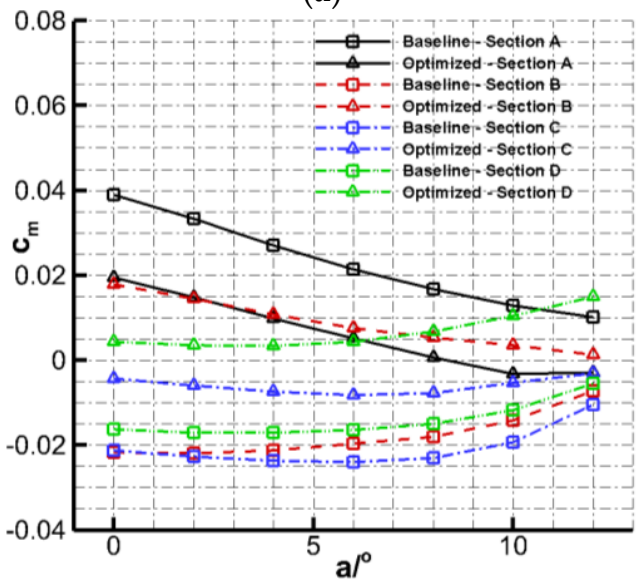

(c)

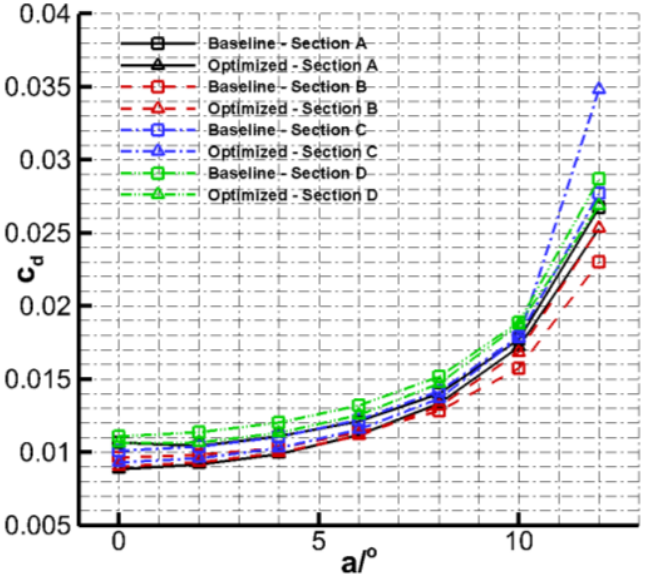

(b)

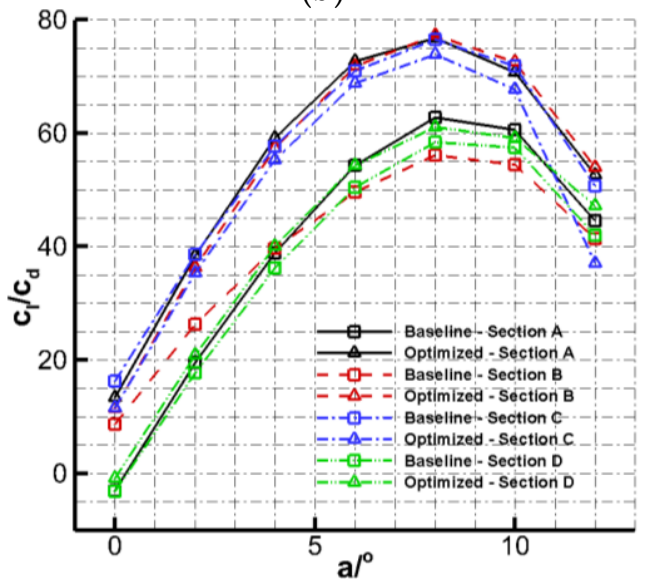

(d)

Figure 11. Comparison of the sectional airfoil performance between before and after the optimization. (a) Lift performance. (b) Drag performance. (c) Pitching performance. (d) Lift-to-drag performance.

\subsection{BWB Configuration Performance}

Figure 12 depicts the comparison of the baseline BWB configuration and the designed BWB configuration generated with the optimized sectional airfoils. Figure 13 shows the comparison of aerodynamic performance. The results suggest that, as compared with the maximum lift-to-drag ratio of 17.24 for the baseline configuration at $\alpha=6^{\circ}$, a maximum lift-to-drag ratio of 20.08 for the designed configuration at $\alpha=4^{\circ}$ represents a $16.59 \%$ increase; furthermore, the pitching performance of the designed configuration is significantly improved as compared with that of the baseline configuration, both the pitching moment at the cruise state $\left(C_{\mathrm{L} \text {, cruise }}=0.2 ; C_{\mathrm{M} \text {, cruise }} \approx 0.0\right)$ and the static stability margin $\left(\Delta C_{\mathrm{M}} / \Delta C_{\mathrm{L}}=-15.38 \%\right)$ meet the design requirements well. This proves the reliability and feasibility of the aforementioned design process. 


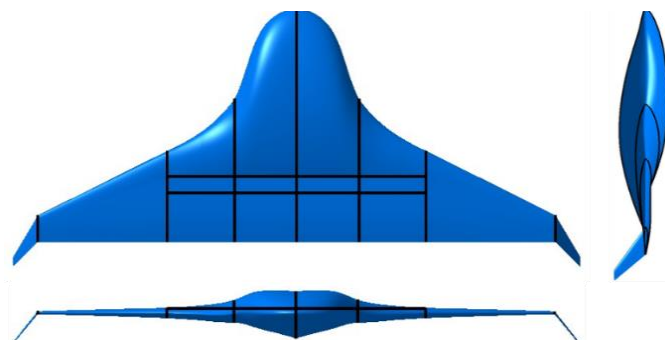

(a)

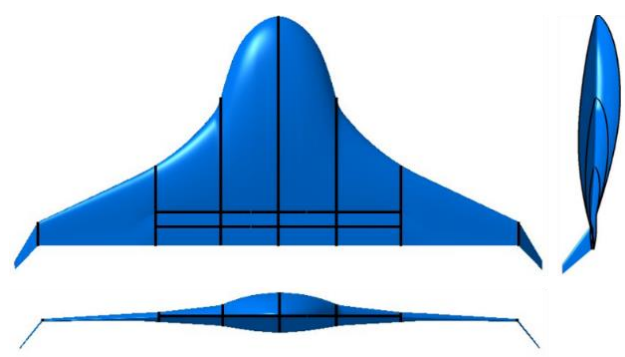

(b)

Figure 12. Comparison of the BWB configuration between before and after the design process. (a) Baseline configuration. (b) Designed configuration.

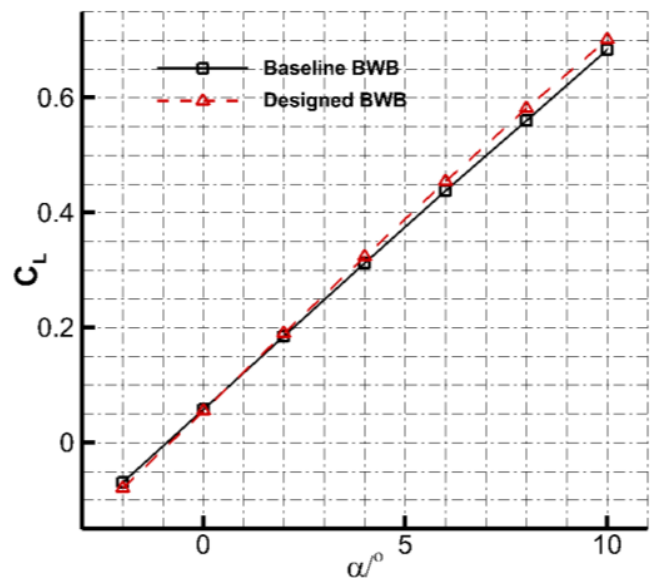

(a)

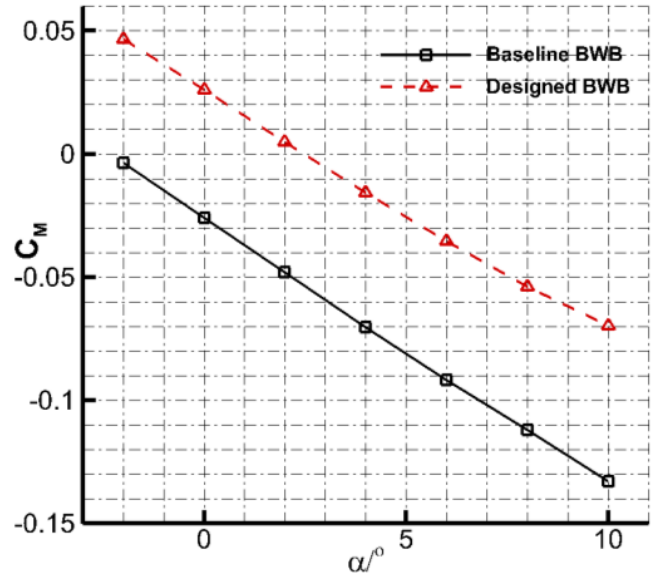

(c)

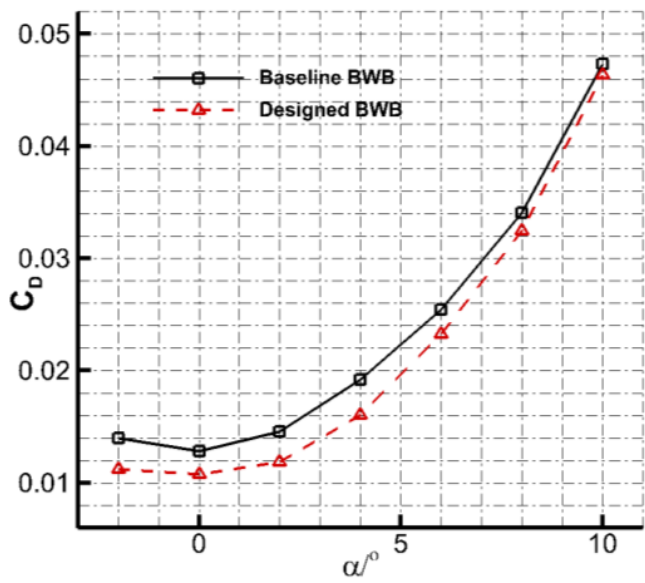

(b)

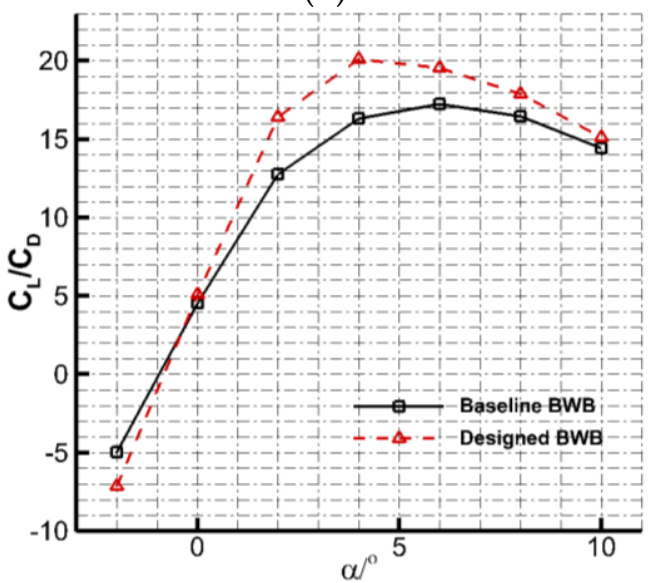

(d)

Figure 13. Comparison of aerodynamic performance of the BWB configuration. (a) Lift performance. (b) Drag performance. (c) Pitching performance. (d) Lift-to-drag performance.

\subsection{DEP Induced Effects Evaluation}

Table 5 illustrates the aerodynamic performance of the BWB configuration with and without the DEP induced effects at $\alpha=2^{\circ}, 4^{\circ}$. It indicates that when compared with aerodynamic performance of the clean BWB configuration, the DEP system which operating at a specified thrust level can lead to $28.23 \%$ lift increment, 38.26\% drag increment, $18.37 \%$ pitching moment reduction and $7.25 \%$ lift-to-drag ratio reduction at $\alpha=2^{\circ}$, and $17.61 \%$ lift increment, $21.06 \%$ drag increment, $42.95 \%$ pitching moment increment and $2.90 \%$ lift-todrag ratio reduction at $\alpha=4^{\circ}$. This means that the lift-to-drag performance of the present BWB configuration will become slightly worse and its static stability margin will also be 
reduced from $15.38 \%$ to $9.44 \%$ when the DEP induced effects are taken into account, but on the whole, the design requirements can still be met.

Table 5. Results of grid independence test for the present BWB configuration.

\begin{tabular}{ccccc}
\hline I & $\begin{array}{c}\text { Aerodynamic } \\
\text { Coefficient }\end{array}$ & BWB & DEP-Based BWB & Increment \\
\hline \multirow{4}{*}{$\alpha=2^{\circ}$} & $C_{\mathrm{L}}$ & 0.1899 & 0.2435 & $+28.23 \%$ \\
& $C_{\mathrm{D}}$ & 0.0115 & 0.0159 & $+38.26 \%$ \\
& $C_{\mathrm{L}} / C_{\mathrm{D}}$ & 16.513 & 15.314 & $-7.25 \%$ \\
& $C_{\mathrm{M}}$ & 0.0049 & 0.0040 & $-18.37 \%$ \\
\hline \multirow{2}{*}{$\alpha=4^{\circ}$} & $C_{\mathrm{L}}$ & 0.3232 & 0.3801 & $+17.61 \%$ \\
& $C_{\mathrm{D}}$ & 0.0161 & 0.0195 & $+21.06 \%$ \\
\hline$/$ & $C_{\mathrm{L}} / C_{\mathrm{D}}$ & 20.075 & 19.492 & $-2.90 \%$ \\
\hline & $C_{\mathrm{M}}$ & -0.0156 & -0.0089 & $+42.95 \%$ \\
\hline
\end{tabular}

\section{Experimental Validations}

\subsection{Wind Tunnel Testing}

The wind tunnel experiments were carried out in the FL-8 $3.5 \mathrm{~m} \times 2.5 \mathrm{~m}$ low speed closed circuit wind tunnel of the Aviation Industry Corporation of China (AVIC) Aerodynamics Research Institute (ARI) in Harbin (see Figure 14). The FL-8 wind tunnel is equipped with an octagonal form test section, and the flow-field quality within the test section is able to reach up to 0.0001 drag measurement accuracy. For this test, atmospheric conditions were measured at wind tunnel location $\left(\rho=1.20978 \mathrm{~kg} / \mathrm{m}^{3}, \mu=1.7853 \times 10^{-5} \mathrm{~Pa} \mathrm{~s}\right.$, $T=14.8^{\circ} \mathrm{C}$ and $p=99 \mathrm{kPa}$ ). Stainless steel was used to manufacture the scale model [24] of the designed BWB configuration in portion with 1: 1.8, and the test velocity was fixed at $68 \mathrm{~m} / \mathrm{s}$, which corresponds to a Reynolds number equal to $2.0 \times 10^{6}$.
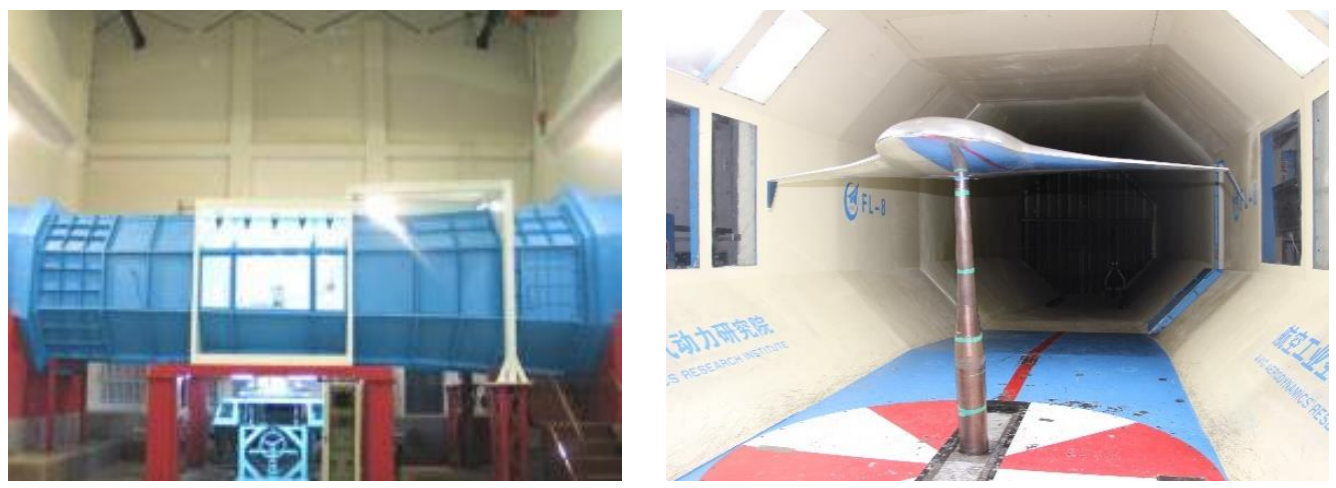

Figure 14. Wind tunnel test in FL-8.

\subsection{Experimental Data Analysis}

\subsubsection{Aerodynamic Characteristics Measurement}

The aerodynamic characteristics of the numerical and experimental results for the designed BWB configuration are compared in Figure 15. According to the results, from $\alpha=-6^{\circ}$ to $\alpha=10^{\circ}$, on the linear behavior of the curves, both the aerodynamic force values and the variation trends are in quite good agreements. As it was expected, a maximum lift-to-drag ratio of 22.31 at $\alpha=4^{\circ}$ can be achieved, and the pitching moment meets the design requirements as well. However, for high angles of attack, the present numerical methods can not exactly predict the stalling performance. Even though the correct prestall angle of attack $\left(\alpha=10^{\circ}\right)$ is presented using the numerical methods, the aerodynamic trends of the whole configuration from $\alpha=10^{\circ}$ to $\alpha=26^{\circ}$ show remarkable differences 
between the numerical and experimental results, which puts forward extremely high computing capability for the separated flow simulations in stall. It is also worth mentioning that soft-stall performance of the designed BWB configuration can be observed from the experimental results, which analogues to the aerodynamic behavior of actual aerial vehicles.

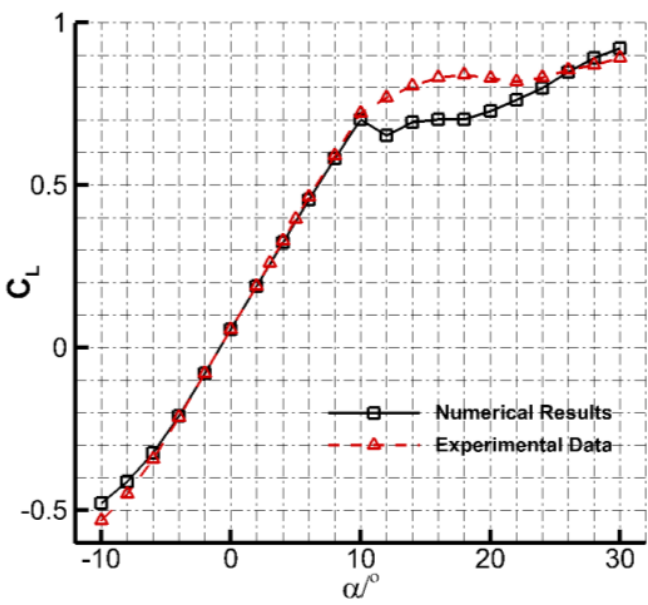

(a)

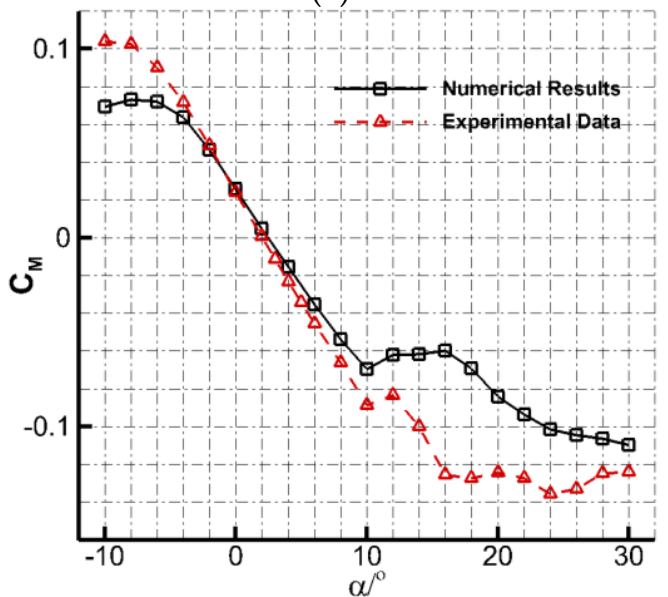

(c)

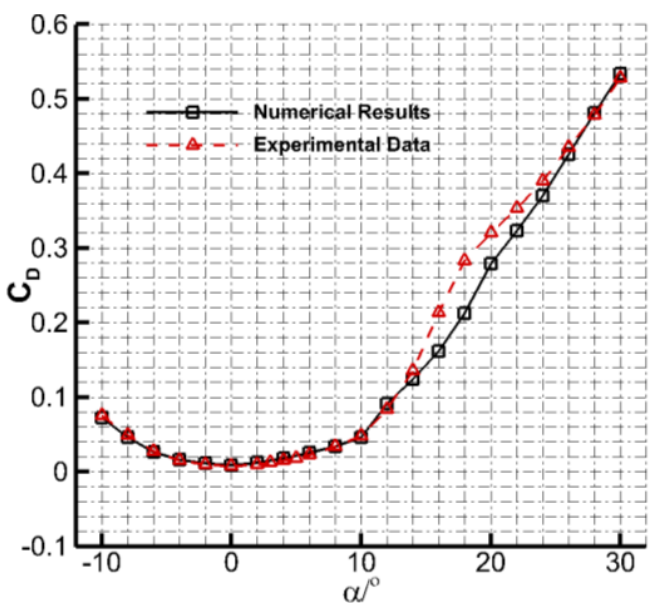

(b)

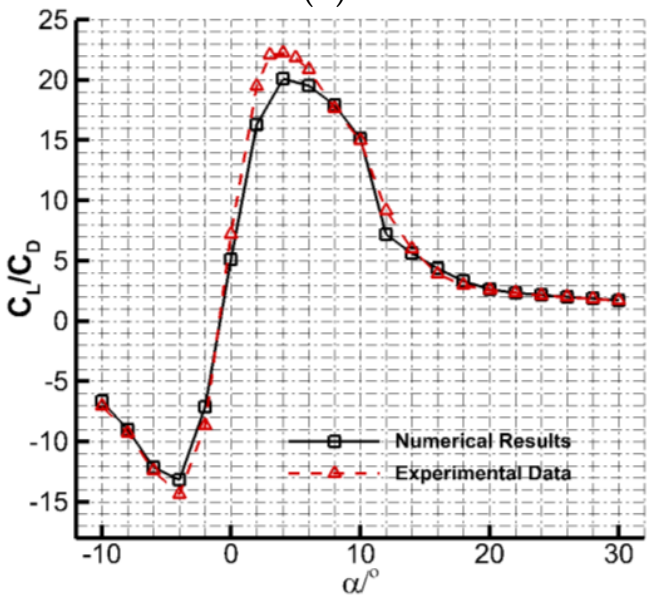

(d)

Figure 15. Comparison of aerodynamic performance between the numerical results and the experimental data. (a) Lift performance. (b) Drag performance. (c) Pitching performance. (d) Lift-todrag performance.

\subsubsection{Surface Flow Visualization}

In order to further explore the differences between the present numerical methods and wind tunnel tests in predicting the aerodynamic performance of the BWB configuration at high angles of attack, the surface flow distributions on the upper surface of the designed BWB configuration of both numerical and experimental results are compared and analyzed in Figures 16 and 17, and the angle of attack studied varies from $\alpha=8^{\circ}$ to $\alpha=28^{\circ}$ with an angle interval of $4^{\circ}$. 


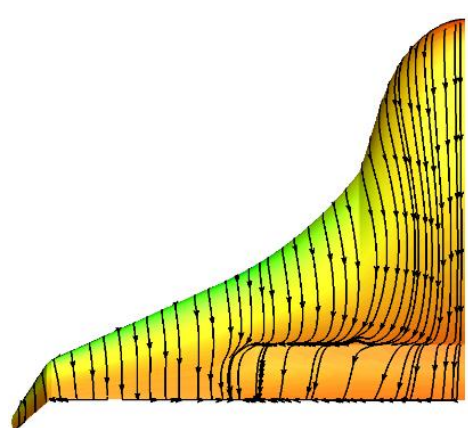

$\begin{array}{lllll}\text { C }_{\text {P: }} & -5.95693 & -3.86968 & -1.78243 & 0.304822\end{array}$

(a)

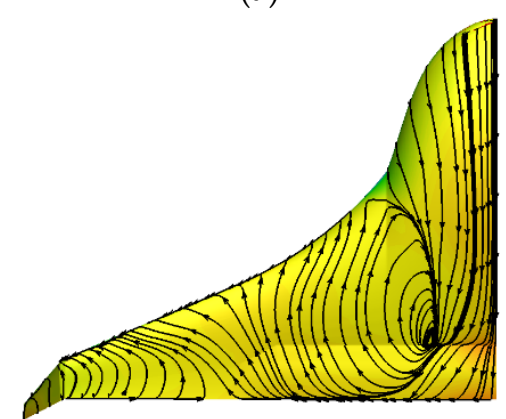

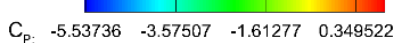

(d)

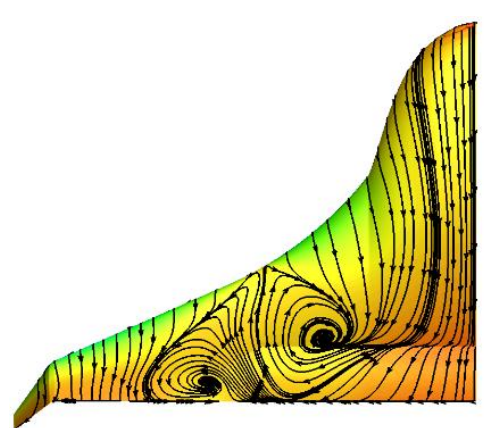

$\begin{array}{lllll}\text { C. } & -5.98314 & -3.88803 & -1.79293 & 0.302179\end{array}$

(b)

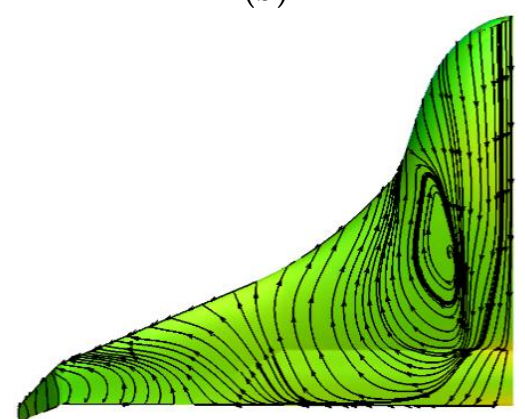

\begin{tabular}{ccccc} 
& & & & \\
\hline C. & -3.49083 & -2.14095 & -0.791079 & 0.558796
\end{tabular}

(e)

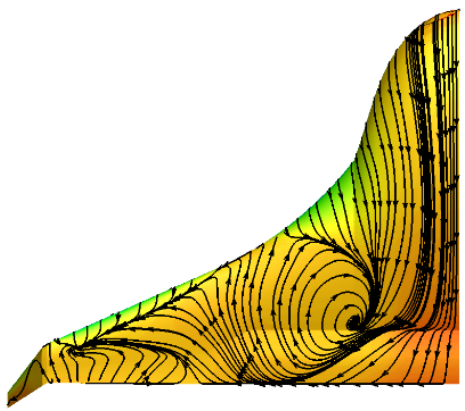

$\begin{array}{lllll}C_{P},-7.02956 & -4.62046 & -2.21136 & 0.197749\end{array}$

(c)

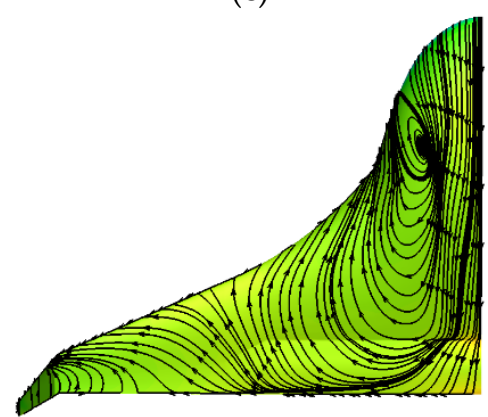

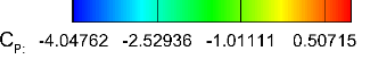

(f)

Figure 16. Numerical surface flow distribution development with angle of attack. (a) $\alpha=8^{\circ}$. (b) $\alpha=12^{\circ}$. (c) $\alpha=16^{\circ}$. (d) $\alpha=20^{\circ}$. (e) $\alpha=24^{\circ}$. (f) $\alpha=28^{\circ}$.

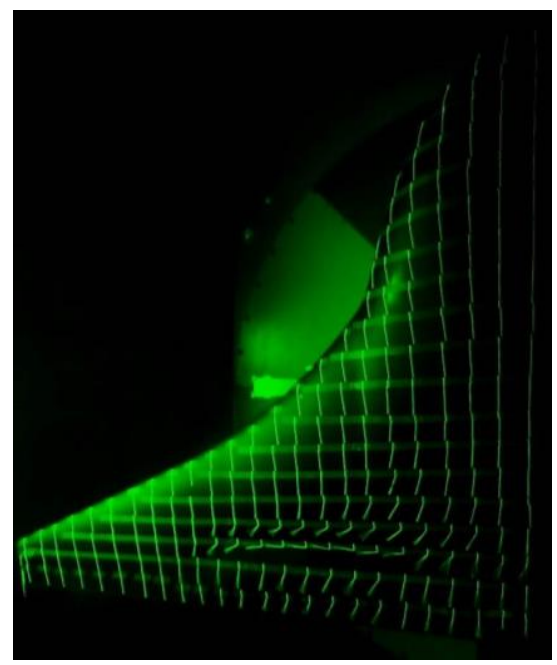

(a)

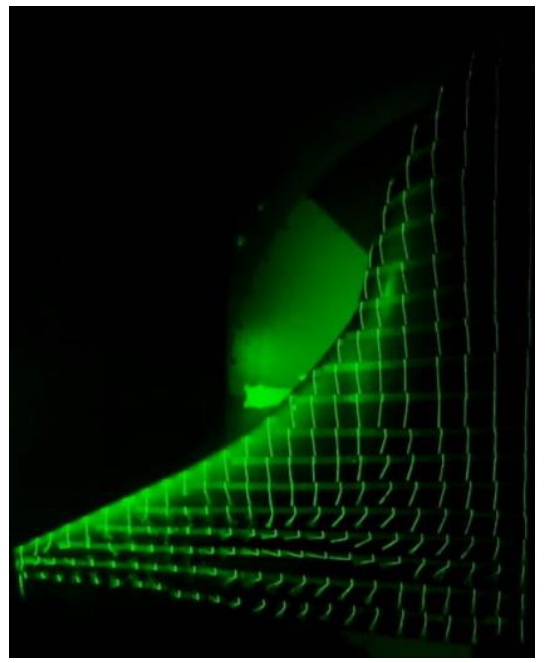

(b)

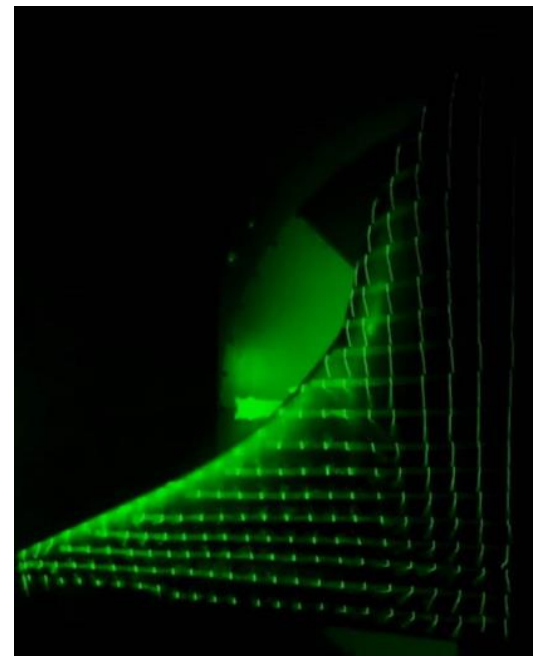

(c)

Figure 17. Cont. 


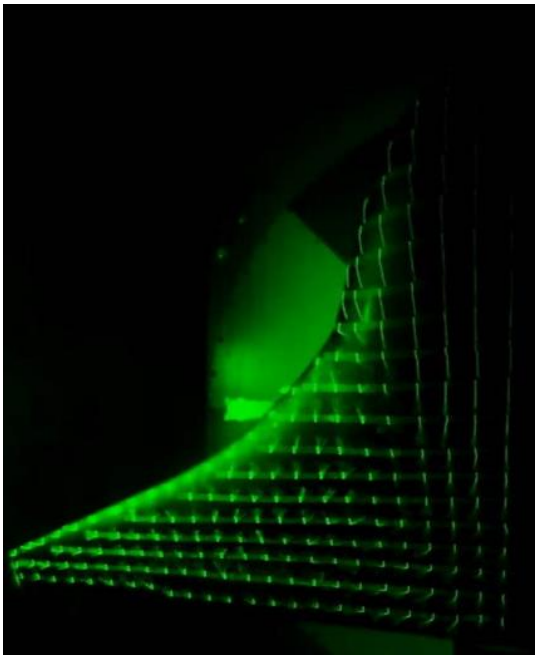

(d)

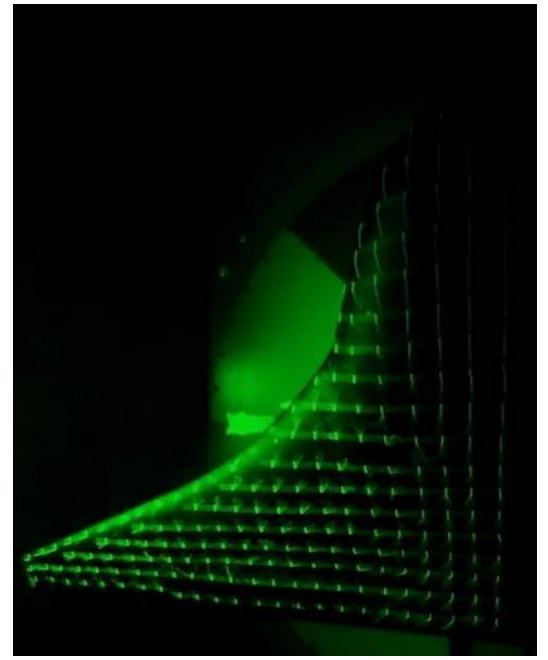

(e)

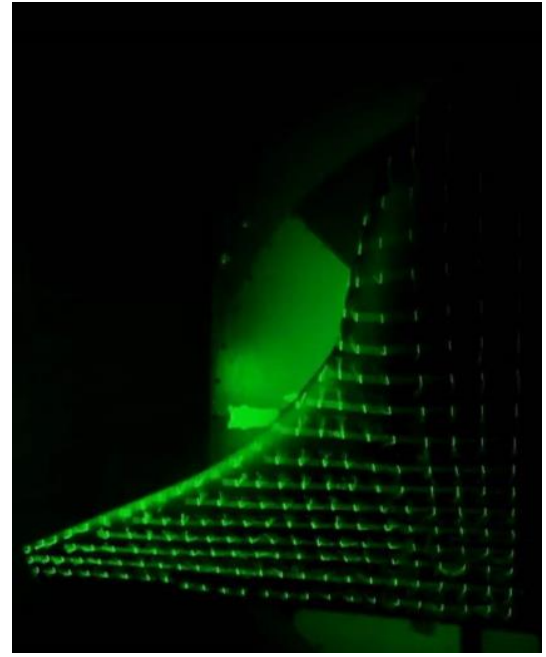

(f)

Figure 17. Experimental surface flow distribution development with angle of attack. (a) $\alpha=8^{\circ}$. (b) $\alpha=12^{\circ}$. (c) $\alpha=16^{\circ}$. (d) $\alpha=20^{\circ}$. (e) $\alpha=24^{\circ}$. (f) $\alpha=28^{\circ}$.

At $\alpha=8^{\circ}$, the numerical results agree with the experimental observation very well, and the flow is completely attached on the upper surface of the designed BWB configuration except for the presence of span-wise flow deflection along the front edge of the planar region.

At $\alpha=12^{\circ}$, the numerical results show that large-scale horizontal vortex rolls are formed within the central region due to the intensification of the described span-wise flow deflection; however, the experimental results suggest that flow separation occurs in some local areas near the wingtip. This means that the numerical simulation overestimates the adverse effects of the span-wise flow deflection when compared with the experimental results, thus leads to the notable differences in predicting the stall performance of the designed BWB configuration (see Figure 15).

As the angle of attack increases, the vortices have gradually become stronger and larger, and most of the surface flow is separated at such high angles of attack. According to the numerical analysis, the horizontal vortex rolls induced by the span-wise flow deflection expand to both sides as the angle of attack increases, in contrast, the vortices observed in this experiment steadily move inboard from near the wingtip to the "fuselage" of the designed BWB configuration. It proves that both the separated flow mechanism and developments at high angles of attack described by the numerical and experimental results are quite different, which further helps understand the discrepancy in stall performance of the BWB configuration as mentioned above.

\section{Conclusions}

The aerodynamic design of a small new-conceptual DEP-based BWB UAV has been developed in this study. Based on the specified DEP installation constraints, a segmented parameterization method of airfoil and a high-efficiency optimization design process of $\mathrm{BWB}$ configuration is developed and demonstrated. Both the CFD simulations and wind tunnel experiments serve as methods to evaluate the design quality of the present BWB configuration, verifying that all the design requirements have been achieved.

The results obtained with analytical, computational and experimental methods indicate that a well-performed DEP-based BWB configuration can be designed by using the parameterization methods and design optimization framework established in this paper, as a result, a maximum lift-to-drag ratio of 22.31 at $\alpha=4^{\circ}$ is achieved while both the pitching moment and the static stability margin at the cruise state meet the design requirements well. However, due to the assumptions that have been made to simplify the design problem, only the BWB configuration is designed under specified DEP installation 
constraints, and the DEP induced effects is analyzed based on a simplified model after the design is completed. Moreover, it appears that the present numerical methods are not adequate to model the performance of the designed BWB configuration at high angles of attack, which is closely related to the development of the flow-field. In subsequent studies, it will be of great importance to further improve the numerical methods and study the airframe/propulsion integrated aerodynamic performance; only in this way can we reach the real goals of the high-performance DEP-based BWB configuration.

Author Contributions: Conceptualization, K.W.; methodology, K.W.; software, K.W.; validation, K.W. and Z.Z.; formal analysis, K.W.; investigation, K.W.; resources, K.W.; data curation, K.W.; writingoriginal draft preparation, K.W.; writing - review and editing, K.W.; visualization, K.W.; supervision, K.W.; project administration, Z.Z.; funding acquisition, Z.Z. All authors have read and agreed to the published version of the manuscript.

Funding: This research was funded by EQUIPMENT PRE-RESEARCH PROJECT, grant number 41411020401 .

Acknowledgments: The authors would like to express their thanks for the support from Mali Han and Xintong Wang in such unusual years 2020 2022.

Conflicts of Interest: The authors declare no conflict of interest.

\section{References}

1. Hyoungjun, K.; Mengsing, L. Shape Design Optimization of Embedded Engine Inlets for N2B Hybrid Wing-Body Configuration. Aerosp. Sci. Technol. 2013, 30, 128-149.

2. Hyoungjun, K.; Mengsing, L. Flow Simulation and Optimal Shape Design of N3-X Hybrid Wing Body Configuration Using a Body Force Method. Aerosp. Sci. Technol. 2017, 71, 661-674.

3. Kim, H.D. Distributed Propulsion Vehicles. In Proceedings of the 27th International Congress of the Aeronautical Sciences, Nice, France, 19-24 September 2010. ICAS Paper 2010-1.1.3.

4. Rudi, K.; Lorenzo, R.; Andrew, R.; Panagiotis, L.; Georgios, D.; Riti, S. An Assessment of Distributed Propulsion: Part B-Advanced Propulsion System Architectures for Blended Wing Body Aircraft Configurations. Aerosp. Sci. Technol. 2016, 50, 212-219.

5. $\quad$ Andrew, T.W.; John, R.H.; Christopher, J.H.; Cale, H.Z. Integrated Aerodynamic Benefits of Distributed Propulsion. In Proceedings of the 53rd AIAA Aerospace Sciences Meeting, Kissimmee, FL, USA, 5-9 January 2015. AIAA 2015-1500.

6. Michael, F.K. Aero-Propulsive Coupling of an Embedded, Distributed Propulsion System. In Proceedings of the 33rd AIAA Applied Aerodynamics Conference, Dallas, TX, USA, 22 June 2015. AIAA 2015-3162.

7. Aaron, T.P.; Phillip, J.A.; Michael, F.K. Aero-Propulsive and Propulsor Cross-Coupling Effects on a Distributed Propulsion System. J. Aircr. 2018, 55, 2414-2426.

8. Sebastian, S.; Tomas, G. Performance analysis of turbo-electric propulsion system with fuselage boundary layer ingestion. Aerosp . Sci. Technol. 2021, 109, 106412. [CrossRef]

9. Qin, N.; Vavalle, A.; Moigne, A.; Laban, M.; Hackett, K.; Weinerfelt, P. Aerodynamic considerations of blended wing body aircraft. Prog. Aerosp. Sci. 2004, 40, 321-343. [CrossRef]

10. Zhenli, C.; Minghui, Z.; Yingchun, C.; Weimin, S.; Zhaoguang, T.; Dong, L.; Binqian, Z. Assessment on critical technologies for conceptual design of blended-wing-body civil aircraft. Chin. J. Aeronaut. 2019, 32, 1797-1827.

11. Minghui, Z.; Zhenli, C.; Zhaoguang, T.; Wenting, G.; Dong, L.; Changsheng, Y.; Binqian, Z. Effects of stability margin and thrust specific fuel consumption constraints on multi-disciplinary optimization for blended-wing-body design. Chin. J. Aeronaut. 2019, 32, 1847-1859.

12. Mader, C.; Martins, J. Stability-constrained aerodynamic shape optimization of flying wings. J. Aircr. 2013, 50, 1431-1449. [CrossRef]

13. Panagiotou, P.; Fotiadis-Karras, S.; Yakinthos, K. Conceptual design of a blended wing body MALE UAV. Aerosp. Sci. Technol. 2018, 73, 32-47. [CrossRef]

14. Payam, D.; Amir, N. The aerodynamic design evaluation of a blended-wing-body configuration. Aerosp. Sci. Technol. 2015, 43, 96-110.

15. Heiko, E.; Wilfried, B.; Alan, M. Implementation of a multi-level optimization methodology within the e-design of a blended wing body. Aerosp. Sci. Technol. 2004, 8, 145-153.

16. Parviz, Z.; Mohsen, S. An efficient aerodynamic shape optimization of blended wing body UAV using multi-fidelity models. Chin. J. Aeronaut. 2018, 31, 1165-1180.

17. Kapsalis, S.; Panagiotou, P.; Yakinthos, K. CFD-aided optimization of a tactical blended-wing-body UAV configuration using the Taguchi method. Aerosp. Sci. Technol. 2021, 108, 106395. [CrossRef]

18. Raymond, M.H.; Preston, A.H. Wing design by numerical optimization. J. Aircr. 1978, 15, 407-412. 
19. Menter, F.R. Two-equation eddy-viscosity turbulence models for engineering applications. AIAA J. 1994, 32, 1598-1605. [CrossRef]

20. Sun, M.; Zhan, H. Application of Kriging Surrogate Model for Aerodynamic Shape Optimization of Wing. Acta Aerodyn. Sinca 2011, 29, 759-764.

21. Wang, K.; Zhou, Z.; Zhu, X.; Guo, J.; Fan, Z. Reconstruction design of the propeller induced flow-field based on the aerodynamic loading distributions. Acta Aeronaut. Astronaut. Sin. 2020, 41, 123118. [CrossRef]

22. Hu, X.Z.; Chen, X.Q.; Zhao, Y.; Yao, W. Optimization Design of Satellite Separation Systems Based on Multi-Island Genetic Algorithm. Adv. Space Res. 2014, 53, 870-876. [CrossRef]

23. Elisa, M.; Andrea, B.; Domenico, Q.; Renato, T. Gradient based empirical cumulative distribution function approximation for robust aerodynamic design. Aerosp. Sci. Technol. 2021, 112, 106630. [CrossRef]

24. Wang, G.; Zhang, M.; Tao, Y.; Li, J.; Li, D.; Zhang, Y.; Yuan, C.; Sang, W.; Zhang, B. Research on analytical scaling method and scale effects for subscale flight test of blended wing body civil aircraft. Aerosp. Sci. Technol. 2020, 106, 106114. [CrossRef] 